\title{
Is It Possible for Pigou Tax and Coase Scheme Working Together? A New Externality Elimination Framework from Relation and Network Perspective
}

\author{
Yanjie Jiang*, Zhuoqun Du, Peilin Wu \\ School of Business, Shandong University, 180 Wenhua Xilu, Huancui District, Weihai 264209, China
}

\begin{abstract}
The extensive use of traditional fossil energy will produce huge environmental or health negative externalities. When it refers to the case of Private Passenger Vehicle (PPV), it exhausts a large amount of air pollutants, which will cause serious health damage to people. Based on the relation and network perspective, examining the traditional externality elimination mechanism-Pigou Tax and Coase scheme, can better summarize their advantages and disadvantages, and propose a new externality elimination framework accordingly. The research poses a new externality elimination framework that combines the advantages of them. It can not only realize the compensation for the health damaged under the Pigou tax, but also make full use of the market disclosure advantage of the Coase scheme for infringement preferences. The research first explains the framework of externality elimination based on relation and network perspective, and reveals that the essence of externality elimination is to change the asymmetric relation of interests into a symmetrical one. Then the study explains the property rights and pollution rights in the Coase scheme also based on relation and network perspective, and believes that property rights are to ensure no externality. Finally, using the social welfare maximization model, the Coase scheme pollution authority amount is included in the indirect utility objective function of a gasoline or new energy vehicle throughout its life cycle, and then the overall social welfare expected to purchase a car is investigated, in order to obtain the substitution relationship between the amount of authority and the amount of compensation, which plays a key role of the new externality elimination framework.
\end{abstract}

\section{Introduction}

The policy management and economic theory about the elimination of externalities can be divided into two categories: Pigou tax and Coase scheme. (ExternE, 2005) In the case of negative externalities of health damage caused by air pollutant emissions from PPV, there is no relation channel between the PPV owner and the health damaged person to carry the flow of damage compensation benefits, and the potential relation between the two, which is a one-direction negative utility flow, explains the main reason for the existence of this negative externality. (Yanjie Jiang et al., 2019)

From the perspective of relation and network, Pigou Tax (Arthur C. Pigou, 1932) provides an idea for the research: the government is the main body of taxation, collects environmental taxes from taxpayers, and then subsidizes to the injured. In this process, the government is an intermediary node in the network located between the taxpayer and the subsidy object, it plays the role of carrying the compensation benefit flow (environment tax). (Yanjie Jiang et al., 2019)

The Coase scheme solves externalities through market mechanism. (Weber R.H. 2017) First, it circumvents the high operating cost of the government in Pigou tax, and on the basis of establishing a tradable pollution right, reflects the environmental protection or marginal tendency of the micro-individual through the market mechanism. However, from the practical application, the Coase scheme only runs between the offenders, and there is no compensation for the victim.

\section{The meaning of the Pigou Tax externality elimination mechanism from relation and network perspective}

Based on the relation and network perspective, a main reason for the existence of externalities is the existence of potential relation and the absence of compensation flows. The cut point and bridge model in graph theory can provide the mathematical basis for the relation building.

The definition of cut point and bridge in graph theory is: let $\mathrm{G}$ be a graph and $\mathrm{v}$ be a vertex of $\mathrm{G}$. If the number of connected branches of G-v is greater than the number of connected branches of $\mathrm{G}$, then $\mathrm{v}$ is called a cut point of $\mathrm{G}$. Let $\mathrm{G}$ be a graph, and $\mathrm{x}$ be an edge of $\mathrm{G}$. If the number of connected branches of G-x is greater than the number of connected branches of $\mathrm{G}$, then call $\mathrm{x}$ a bridge of $\mathrm{G}$, or cut edge.

\footnotetext{
${ }^{*}$ Corresponding author: jiangyanjie_sdu@163.com
} 


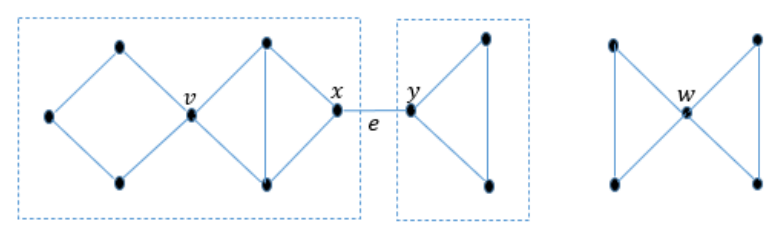

Fig.1. A graph with cut points v, x, y, w and edge e

It can be seen from Fig. 1 that if the edge e is removed, the figure will become three unconnected branches, and the left side will be disassembled into two. Since the flow of interest between points $\mathrm{x}$ and $\mathrm{y}$ is carried out through $\mathrm{e}$, the entire flow of interest in the dashed frame on the left will no longer be exchanged with the flow of interest in the dashed frame on the right. Similarly, if the midpoint $\mathrm{w}$ of the connected branch on the right side of the original image is removed, the connected branch on the right side will also be disassembled into two, and no profit flow interaction can be performed between them. Therefore, the cut point $\mathrm{w}$ and the bridge e have an important network connectivity status.

In the economic sense, the appearance of cut points or bridges is an image description of the internalization process of externalities. Because internalization means that the aggressor and the victim (or group) have changed from an asymmetric interest relation to a symmetrical one. If you want to change the non-equal part of interest flow and transfer it to the "victim", it will inevitably require the emergence of new nodes or connections, and form a new relation to carry the non-equal part of interest flow.

From a network perspective, although the cut point and the bridge provide connectivity for two unconnected branch networks, it also has an obvious shortcoming, that is, there is no direct connection between the specific offender and the victim. As in the case of the study, it is impossible to establish a direct relation between patients who die prematurely and the specific offenders that cause air pollution. Therefore, if the intermediary point is individual-neutral, then it will be just a transit calculation center of interest flow (health damages compensation), and any request that requires it to find a direct responsible person will greatly increase social costs.

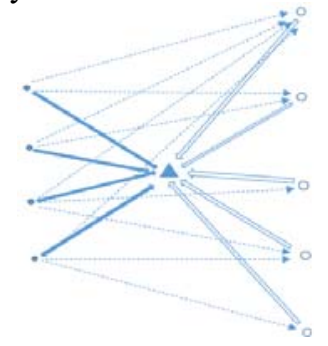

Fig. 2. Network for eliminating externalities caused by PPV with cut point

In Fig. 2, the solid circle on the left represents the PPV owner, the hollow circle on the right represents the health damage victim, and the solid triangle in the middle represents the cut point, like government, which is responsible for transferring the compensation interest flow. The dotted arrow indicates the negative utility flow of the PPV vehicle owner group to the victim's health damage, representing the potential relation between the PPV owner group and the victim group before the cut point emergence; the solid thick arrow line represents the compensation benefit flow, which should be equally related to the violation negative utility flow, while the nature is opposite. It flows to the cut point first, and then is distributed to the victim by the cut point according to the scale of each health damage observation point; the hollow thick arrow line represents the victim's claim for damage (Punishment), which is a negative value for the cut point, and for the victim, the negative utility flow input from the aggressor and exactly offset the negative utility flow output. The compensation is transferred from offender through cut point to the victim, but if it is not neutral, the network will still have externalities.

\section{The meaning of Coase scheme from relation and network perspective}

The main logic of the Coase scheme is to change the individual 's pollution behavior and achieve the purpose of reducing the total externality, by highlighting the comparison of individual's environmental protection and destroying marginal interests through the dual mechanism of pollution quotas and rights transactions.

From the perspective of relation and network, we can understand how property rights ensure no externality. Fig. 3 is an example of the elimination of negative externalities that includes sellers of items (hollow squares).
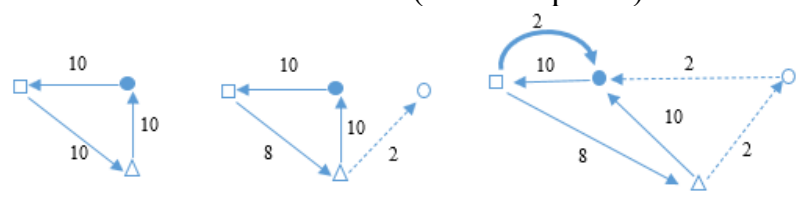

Fig. 3. Property rights and elimination of negative externality

Coase scheme's pollution rights transaction involved in the research gives the owner the right to carry out pollution activities under certain restrictions without being infringed by others. Assuming that the energy consumption level per person per year of pollution rights is 1000 liter $(\mathrm{L})$ of gasoline, the lower part than his actually consumption, like $1000-800=200$, can be taken out and sold on the market. When a PPV car owner with a strong environmental awareness consumes only $800 \mathrm{~L}$ a year, it means that the right is not fully used, which means that the corresponding right of $200 \mathrm{~L}$ is not used. If a person who does not pay much attention to environmental protection and consumes $1200 \mathrm{~L}$ of energy per year, he not only runs out of $1,000 \mathrm{~L}$ of rights, but also needs to get $200 \mathrm{~L}$ of rights, then he can buy the pollution rights corresponding to 200L from owners of environmental protection PPV. The most important thing is the following market competition logic. If the initial state is an environmentally unfriendly society, almost all PPV car owners need to purchase pollution rights, then the pollution rights in the hands of environmentally friendly PPV car owners become scarce items, the price will be very high, which means that for unfriendly car owners, the marginal environmental protection benefits are greater than the marginal environmental damage costs, so it will 
attract everyone to change to environmentalists. When everyone's annual energy consumption is below 1000L, the limit will be meaningless. Therefore, when the Coase scheme is in operation, it is necessary to formulate a mechanism for gradually reducing the pollution authority. For example, when the average energy consumption drops below 1000L, the annual limit of 1000L for all car owners can be reduced to $800 \mathrm{~L}$, so that the health damage or other externalities corresponding to energy consumption will gradually decrease due to the existence of market competition mechanisms. However, due to the existence of energy-consuming behavior, after all, air pollutants are still emitted, and there must be health damage externality. Therefore, the Coase scheme cannot compensate the victims. This is also a disadvantage of the Coase scheme.

\section{New externality elimination framework combining the advantages of Pigou Tax and Coase scheme}

From the perspective of relation and network, a new externality elimination framework is: the government sets a cut point, builds a similar "bridge" compensation channel that connects PPV owner group and healthdamaged group, and then implements Coase scheme within the PPV owners.

The most important thing in the new framework is how the government in Pigou tax acts as an intermediary cut point, and how to determine the level of pollution authority in the Coase scheme and the Pigou tax burden. In the Pigouvian tax, the government should be an information collection, data calculation and transfer payment center, which is responsible for collecting information on the externality of pollution including air pollutants caused by the use of motor vehicles, and all external monetization assessment information of health damage observation points. Then, according to the principle of maximizing social welfare, and considering the practical feasibility and the will of the government to a certain extent, the health damage tax level of Pigou tax and the level of pollution authority in the Coase scheme are determined. The government transfers the fuel consumption tax levied by the government between health damage observation points according to a certain proportion and amount on the basis of health damage externality monetization assessment.

The new externality elimination framework that combines the advantages of the Pigou tax and the Coase scheme reflects the dual pollution control of PPV. One is the tax burden in the Pigou tax, and the second is the pollution rights in the Coase scheme (corresponding to the energy consumption limit). In the new framework, the tax rate for gasoline consumption per unit mileage is set to $t$, and the initial year limit control level for pollution rights is set to $a^{0}$ With the implementation of the Coase scheme, the limit control level is assumed to decrease in proportion to $k, k<1$. Its total energy consumption limit within $\mathrm{n}$ years of life is $\mu_{i}^{\tilde{i}}(g)=a^{0} \cdot \frac{1-k^{n}}{1-k}$.

For simplicity of analysis and without loss of general representativeness, it is assumed here that there are only two models of gasoline vehicles and electric vehicles on the market, and the tax burden level per unit of driving mileage is set as $t_{g a s}, t_{e}$, The pollution authority amounts are assumed to be the same as $\tilde{\mu_{i}}(g)$. The actual energy consumption is $\mu_{g a s}^{d}(g), \mu_{e}^{d}(g)$, The energy consumption per unit of mileage is $E E_{g a s}, E E_{e}$. Then the total mileage in the life cycle is $T D_{g a s}=\frac{\mu_{g a s}^{d}(g)}{E E_{g a s}}, T D_{e}=$ $\frac{\mu_{e}^{d}(g)}{E E_{e}}$. The limit mileage is $T D_{g a s}^{\sim}=\frac{\mu_{i}^{\tilde{i}}(g)}{E E_{\text {gas }}}, T D_{e}^{\sim}=\frac{\mu_{i}^{\tilde{i}(g)}}{E E_{e}}$. Suppose that the subsidy for the purchase of electric vehicles is $s$, and the cost or price per unit of travel distance is $p_{\text {gas }}, p_{e},\left(p_{\text {gas }}>p_{e}\right)$.

Because there are many PPVs in the market, and PPV has no absolute energy consumption level corresponding to monopoly power, so this market can be regarded as a completely competitive market. Then both supply and demand are price takers, giving the reason the equilibrium price of the unit energy consumption pollution right can be set to a fixed number, such as permits ${ }^{*}\left(p^{*}\right)$. Suppose the individual income is $I$, the prices of the cars are $P_{\text {gas }}, P_{e}$ respectively, and the general compound commodity consumed other than the mileage is $x$ and the price is 1 . Drawing on the study of Holland S P, Mansur E T, Muller N Z, et al. (2016), and incorporating the pollution authority of the Coase scheme into it, the indirect utility objective function of purchasing a gasoline car over its entire life cycle can be expressed as:

$$
\begin{gathered}
\qquad V_{\text {gas }}=\max _{x, T D_{\text {gas }}} x+f\left(T D_{\text {gas }}\right) \\
\text { s.t. } x+\left(p_{\text {gas }}+t_{\text {gas }}\right) \\
T D_{\text {gas }}+p^{*}\left(\mu_{\text {gas }}^{d}(g)-\mu_{i}^{\sim}(g)\right) \\
=I-P_{\text {gas }}
\end{gathered}
$$

Among them, $f(\cdot)$ is a concave function (diminishing marginal utility of mileage). Similarly, the indirect utility objective function for buying electric vehicles is:

$$
\begin{gathered}
V_{e}=\max _{x, T D_{e}} x+h\left(T D_{e}\right) \\
\text { s.t. } x+\left(p_{e}+t_{e}\right) T D_{e}+p^{*}\left(\mu_{e}^{d}(g)-\mu_{i}^{\tilde{i}}(g)\right) \\
=I-P_{e}+s
\end{gathered}
$$

Among them, $h(\cdot)$ is also a concave function. The choice of gasoline or electric vehicles can be regarded as a discrete choice. According to traditional research, it is assumed that the two purchase choices are affected by the i.i.d. random variables $\epsilon_{g a s}$ and $\epsilon_{e}$ respectively, and they obey $\left(0, \mu^{2} \cdot \pi^{2} / 6\right)$ value distribution, $\mu$ is a parameter. Then, you can define:

$$
u_{g a s}=V_{g a s}+\epsilon_{g a s}, u_{e}=V_{e}+\epsilon_{e}
$$

When $u_{\text {gas }}>u_{e}$, the owner will choose a gasoline car. The probability of occurrence is:

$$
\theta \equiv P\left(u_{g a s}>u_{e}\right)=\frac{\exp \left(\frac{V_{g a s}}{\mu}\right)}{\exp \left(\frac{V_{g a s}}{\mu}\right)+\exp \left(\frac{V_{e}}{\mu}\right)}
$$

The expected utility of buying a car is (De Borger B, Mayeres I, 2007):

$$
E\left[\max \left[u_{g a s}, u_{e}\right]\right]=\mu \cdot \ln \left(\exp \left(\frac{V_{e}}{\mu}\right)+\exp \left(\frac{V_{g a s}}{\mu}\right)\right)
$$


So how will the government set tax rate and pollution authority? From the government's standpoint, he is concerned about the overall welfare of the society. Assuming that the government's fiscal revenue is $R$, and the health damage caused by PPV unit mileage is $\delta_{\text {gas }}$, $\delta_{e}$, then the expected health damage scale per unit vehicle is:

$$
\mathrm{H}_{G}=\theta \cdot \delta_{\text {gas }} \cdot T D_{\text {gas }}+(1-\theta) \cdot \delta_{e} \cdot T D_{e}
$$

The overall expected social benefits of buying a car is:

$$
\begin{gathered}
\mathrm{W}=\mu \ln \left(\exp \left(\frac{V_{e}}{\mu}\right)+\exp \left(\frac{V_{g a s}}{\mu}\right)\right)+R-\left(\theta \delta_{g a s} T D_{g a s}\right. \\
\left.+(1-\theta) \delta_{e} T D_{e}\right)
\end{gathered}
$$

In Holland S P, Mansur E T, Muller N Z, et al. (2016), provides a similar related formula derivation in appendix. The research focuses on the establishment of pollution authority, which can be derived after derivation:

$$
\begin{gathered}
p^{*} E E_{g a s}-\left(\delta_{g a s} \theta \frac{\partial T D_{\text {gas }}}{\partial T D_{\text {gas }}^{\sim}}+\delta_{e}(1-\theta) \frac{\partial T D_{e}}{\partial T D_{\text {gas }}^{\sim}}\right)=0 \\
p^{*} E E_{e}-\left(\delta_{g a s} \theta \frac{\partial T D_{\text {gas }}}{\partial T D_{e}^{\sim}}+\delta_{e}(1-\theta) \frac{\partial T D_{e}}{\partial T D_{e}^{\sim}}\right)=0
\end{gathered}
$$

Because the study does not distinguish between gasoline vehicles and electric vehicles for pollution authority, which is both set to $\mu_{i}^{\sim}(g)$, so the derivation results are equivalent. Taking the first derivation result as an example, it is shown that the establishment of the pollution authority should make the expected change in health damage caused by gasoline or electric vehicles equal to the energy consumption cost per unit distance. Assuming that in order to control the use of gasoline vehicles and reduce the travel distance corresponding to the amount of pollution authority, under normal circumstances, PPV will reduce the actual mileage and the size of the expected health damage (social benefits) that can be avoided, just be reflected by the Coase scheme's price mechanism.

The study believes that in the idea of eliminating the externality that combines the advantages of the Pigou tax and the Coase scheme, the Pigou tax must be transferred to the health-damaged. But the tax rate must be set to reflect the role played by the Coase scheme, that is, there is interaction between the two. Here is different from Holland S P, Mansur E T, Muller N Z, et al. (2016), that the PPV owner's unit travel distance cost composition is increased by $p^{*} E E_{g a s}$ (gasoline vehicle) and $p^{*} E E_{e}$ (electric vehicle). If we use $t_{g a s}^{\prime}$ instead of $t_{\text {gas }}+p^{*} E E_{\text {gas }}$, meaning $t_{g a s}^{\prime}=t_{\text {gas }}+p^{*} E E_{\text {gas }}$, at the same time $t_{e}^{\prime}=t_{e}+p^{*} \cdot E E_{e}$, then according to the derivation of Holland et al. (2016), we will get:

$$
\begin{gathered}
t_{g a s}+p^{*} \cdot E E_{g a s}=\delta_{g a s} \\
t_{e}+p^{*} \cdot E E_{e}=\delta_{e}
\end{gathered}
$$

This fully shows that the energy consumption cost per unit distance in the Pigou tax and the Coase scheme in the new externality elimination framework has a substitution effect, and it is optimal only when the sum of them and the social loss caused by it are the same. When the direct transfer payment to the victim's health damage (Pigou tax) is set lower, the pollution right price of the Coase scheme will be higher. Conversely, when the direct compensation is higher, the Coase scheme will have a lower transaction price. Moreover, it must be combined with the environment-friendly characteristics of different PPVs and energy consumption per unit distance. The up-two formulas also illustrate the principle of compensation for whoever pollutes, who bears the damage.

\section{Conclusion}

The study analyzes the Pigou Tax and Coase scheme from the perspective of relation and network, and proposes a new framework for eliminating externality that combines the advantages of the two. Mainly to give full play to the role of government intermediary nodes, establish health damage compensation channels between PPV owners and health-damaged persons, and change the status of potential relationships between them. At the same time, the Coase scheme is implemented in PPV owners to allow the market mechanism to expose individual's environmental protection or infringement tendencies, and to improve overall health damage by gradually reducing the level of pollution rights. The study believes that it is completely feasible under the application of new technologies such as big data, cloud computing and the Internet of Things. The most important thing is that the potential relationship and the state of full-scale health violation network cannot be allowed to continue. Direct compensation to the health-damaged person will reflect social fairness and protect the public's health rights, which is also a direct warning and punishment for the offender and the offending behavior.

\section{References}

1. Externalities of Energy: methodology 2005 update[J]. Luxembourg: Office for Official Publications of the European Communities, 2005.

2. Arthur C. Pigou. The Economics of Welfare (4th ed.) (London: Macmillan, 1932)

3. Yanjie Jiang. et al. 2019 IOP Conf. Ser.: Earth Environ. Sci. 401012018.

4. Weber R.H. (2017) Emission Trading Schemes: A Coasean Answer to Climate Change?. In: Mathis K., Huber B. (eds) Environmental Law and Economics. Economic Analysis of Law in European Legal Scholarship, vol 4. Springer, Cham.

5. Holland S P, Mansur E T, Muller N Z, et al. Are there environmental benefits from driving electric vehicles? The importance of local factors[J]. American Economic Review, 2016, 106(12): 3700-3729.

6. De Borger B, Mayeres I. Optimal taxation of car ownership, car use and public transport: Insights derived from a discrete choice numerical optimization model[J]. European Economic Review, 2007, 51(5): 1177-1204. 